\title{
MANAGING PERSONAL FINANCE WIRED FOR WORK SOFT SKILL TRAINING BEKERJA SAMA DENGAN LSM “BULIR PADI FOUNDATION” DAN SMK PERTIWI
}

\author{
Sumani, Christiana Fara Dharmastuti \\ Fakultas Ekonomi dan Bisnis Universitas Katolik Indonesia Atma Jaya, \\ sumani@atmajaya.ac.id
}

\begin{abstract}
The Bulir Padi Foundation, a non-profit organization that has been established in 2002, is committed to contributing to the education of underprivileged children in the suburbs of Jakarta by turning them into foster children. And in 2020, one of the work programs is to produce mentored children who have work skills so that the hope is that they are better prepared to enter the workforce at the entry-level so that they can answer industry needs through providing job readiness training. The Wired For Work Soft Skill Training (W4W) program is a non-formal training program for Bulir Padi Foundation children to produce children who have work skills so that they are expected to be better prepared to enter the world of work at the entry-level so that they can answer industry needs by providing readiness training work. In this W4W Program, Bulir Padi Foundation will collaborate with Atma Jaya University and Pertiwi Vocational High School to a synergy between non-governmental organizations and the academic community in solving social problems, especially in the field of education. Pertiwi SMK students will be facilitated to receive soft skills training to enter the world of work. The material covered in the Wired For Work Soft Skill Training (W4W) training activity this time includes Self management to improve work ethics, Implementing basic communications skills, Implementing the right equality of female and male workers in the workplace, Implementing the quality of grooming, and professional manner, Preparing Job Application and interview test and Manage Personal Finances.
\end{abstract}

Keywords: training, soft skills, Wired for Work, the world of work, personal finance

\begin{abstract}
Abstrak
Yayasan Bulir Padi, sebuah organisasi nirlaba yang sudah berdiri sejak tahun 2002, berkomitmen untuk berkontribusi dalam pendidikan anak-anak kurang mampu di pinggiran Kota Jakarta dengan menjadikan mereka menjadi anak bina. Dan ditahun 2020 ini, salah satu program kerjanya adalah mencetak anakanak bina yang mempunyai ketrampilan kerja sehingga harapannya lebih siap memasuki dunia kerja di entry level sehingga dapat menjawab kebutuhan industri melalui pemberian pelatihan kesiapan kerja. Program Wired For Work Soft Skill Training (WW) merupakan program pelatihan non formal bagi anak bina Yayasan Bulir Padi guna mencetak anak-anak bina yang mempunyai ketrampilan kerja sehingga harapannya lebih siap memasuki dunia kerja di entry level sehingga dapat menjawab kebutuhan industri melalui pemberian pelatihan kesiapan kerja. Dalam Program W4W kali ini, Yayasan Bulir Padi akan bekerja sama dengan Unika Atma Jaya dan SMK Pertiwi sebagai bentuk sinergi antara lembaga swadaya masyarakat dengan civitas akademika dalam menyelesaikan masalah sosial, utamanya dibidang pendidikan. Siswa-siswi SMK Pertiwi akan difasilitasi untuk menerima pelatihan soft skill demi kesiapan mereka memasuki dunia kerja. Materi yang di cover dalam kegiatan Pelatihan Wired For Work Soft Skill Training (W4W) kali ini meliputi Self management to improve work ethics, Implementing basic communications skills, Implementing the right equality of female and male workers in workplace, Implementing the quality of grooming and professional manner, Preparing Job Application and interview test dan Manage Personal Finances
\end{abstract}

Kata kunci: Pelatihan, Softskill, Wired for Work, Dunia kerja, Keuangan Pribadi 


\section{PENDAHULUAN}

Bulir Padi merupakan organisasi lembaga swadaya masyarakat yang membantu anak- anak kurang mampu dengan memberikan mereka beasiswa dan akses untuk pendidikan. Tujuan Yayasan ini adalah untuk memberdayakan anak-anak binaan Bulir Padi sehingga mereka dapat berkembang menjadi pribadi mandiri dan membantu meningkatkan taraf hidup keluarga dan komunitas mereka.

Latar belakang filsafat Bulir Padi adalah seperti tanaman padi yang semakin berisi semakin merunduk artinya semakin tinggi ilmunya semakin rendah hatinya. Harapan kami anakanak Bulir Padi anak-anak binaan berkembang seperti layaknya tanaman padi dan dapat mewujudkan potensi dirinya, meningkatkan ilmunya tetapi tetap rendah hati dalam perjalanan hidupnya.

Saat ini Bulir Padi telah memberikan lebih dari 380 beasiswa untuk anak-anak kurang mampu di Jakarta. Bulir Padi juga menyelenggarakan Acara Tahunan Book Drive (penggalangan buku baru dan bekas layak pakai) dimana sejauh ini lebih dari 2000 buku telah terkumpul untuk Perpustakaan Umum Bulir Padi yang terletak di Palmerah, Jakarta Barat.

Yayasan Bulir Padi, sebuah organisasi nirlaba yang sudah berdiri sejak tahun 2002, berkomitmen untuk berkontribusi dalam pendidikan anakanak kurang mampu di pinggiran Kota Jakarta dengan menjadikan mereka menjadi anak bina. Dan ditahun 2020 ini, salah satu program kerjanya adalah mencetak anak-anak bina yang mempunyai ketrampilan yang dapat menjawab kebutuhan industri melalui pemberian pelatihan kesiapan kerja dengan nama program Mandiri
Berdikari dimana salah satu kegiatannya adalah pelatihan $\mathrm{W} 4 \mathrm{~W}$

Salah satu program kemitraan Yayasan Bulir Padi bersama PLAN International adalah program pemberdayaan ekonomi kaum muda, yakni program Youth Economic Empowerment (YEE) melalui Wired for Work (W4W) project. Program ini diimplementasikan dengan tujuan agar kaum muda marginal, terutama perempuan,

mendapatkan pekerjaan yang layak melalui pekerjaan formal maupun berwirausaha. Saat ini, Bulir Padi sedang mengembangkan sebuah ekosistem digital yang mendukung kaum muda untuk memiliki potensi yang dibutuhkan perusahaan dan mendapatkan pekerjaan, salah satunya dengan memberikan materi pembelajaran online yang dapat diakses oleh semua orang. Indonesia

membutuhkan sekitar 3,2 juta pekerja terampil tambahan per tahun, sementara alokasi anggaran untuk pendidikan non--formal (kejuruan) masih terbatas dan menyebabkan sebagian besar kaum muda tidak dapat mengakses pelatihan. Populasi

Indonesia adalah sekitar 257,89 juta orang, sedangkan jumlah kaum muda Indonesia adalah sekitar 62,06 juta orang atau sekitar 24,07 persen dari total populasi Indonesia. Rasio jenis kelamin (perbandingan antara populasi pria dan wanita) pada tahun 2016 adalah 102,38. Rasio gender ini menunjukkan bahwa jumlah kaum muda laki--laki lebih tinggi daripada perempuan dan sekitar 53 persen kaum muda tinggal di daerah perkotaan.

Data menunjukkan bahwa lama rata-rata pendidikan bagi penduduk Indonesia adalah 6,5 tahun. Berdasarkan data Susenas 2016, rata-rata lama sekolah kaum muda adalah 10,21 tahun 
dan hal ini menunjukkan bahwa kaum muda Indonesia telah menyelesaikan pendidikan sampai kelas 1 Sekolah Menengah Atas atau setara. Namun sayangnya tingkat pendidikan juga tidak menjamin akses ke pekerjaan. Angka pengangguran kaum muda tertinggi berada pada tamatan SMA/sederajat yaitu 17,34 persen, sedangkan jumlah angka pengangguran kaum muda dengan tingkat pendidikan perguruan tinggi dan SMP/sederajat menempati urutan kedua dan ketiga, yaitu 11,93 persen dan 10,70 persen.

Menanggapi isu yang telah dipaparkan diatas, Tim Dosen Universitas Katolik Indonesia Atma Jaya bersama Yayasan Bulir Padi dan SMK Ibu Pertiwi 2 berinisiatif untuk menyelenggarakan pelatihan soft skill sebagai upaya untuk mensukseskan proyek W4W ini.

\section{METODE}

Tujuan kegiatan pelatihan ini adalah memberikan dan menyiapkan lulusan SMK Ibu Pertiwi 2 untuk masuk didunia kerja, utamanya dalam pelatihan softskill sebanyak 5 sesi; Memberikan pengalaman bagi anak bina untuk berinteraksi dengan civitas akademika; Menumbuhkan jiwa semangat belajar dan semangat keluar dari zona nyaman, agar tergerak untuk mempunyai kehidupan yang lebih baik dimasa depan; Membangun relasi antar lembaga.

Pelatihan akan diberikan dalam bentuk Daring yang dibawakan dengan platform Zoom pada tanggal 21-22 Juli 2020. Materi yang di cover dalam kegiatan Pelatihan kali ini meliputi Self management to improve work ethics, Implementing basic communications skills, Implementing the right equality of female and male workers in workplace, Preparing Job Application and interview test, Manage Personal Finances

\section{HASIL DAN PEMBAHASAN}

Pembahasan mengenai topik managing personal finances. Uang adalah alat tukar menukar yang sah dalam lalu lintas perekonomian serta alat yang dapat dipakai untuk melakukan pembayaran. Fungsi Uang adalah sebagai satuan hitung, artinya uang dapat memberikan harga sebuah komoditas. Dengan demikian, nilai suatu barang dapat diukur dan dibandingkan; Sebagai alat transaksi; Sebagai Penyimpanan nilai, artinya uang mampu menyimpan hasil transaksi untuk mengalihkan daya beli dari masa sekarang ke masa mendatang..

Sifat uang antara lain mudah dibawa, tidak mudah rusak dan memiliki ketahanan yang lama, diterima semua orang, memiliki bentuk, warna, dan ukuran yang baku, memiliki kestabilan atau tidak mengalami perubahan sehingga uang mudah dikenali, memiliki jumlah yang tidak berlebihan dan terbatas namun bisa memenuhi kebutuhan.

Tabel 1. Kebutuhan Vs Keinginan

\begin{tabular}{|c|c|c|c|}
\hline No & Aspek & Kebutuhan & Keinginan \\
\hline 1. & Sifat & $\begin{array}{c}\text { Bersifat pokok, } \\
\text { tidak bisa } \\
\text { ditunda, } \\
\text { objektif, ada } \\
\text { batasnya, }\end{array}$ & $\begin{array}{c}\text { Tidak } \\
\text { bersifat } \\
\text { pokok, bisa } \\
\text { ditunda, } \\
\text { subjektif, } \\
\text { tidak ada } \\
\text { batasnya. }\end{array}$ \\
\hline 2. & Dampak & Manfaat & Kepuasan \\
\hline 3. & Tolok Ukur & Fungsi & $\begin{array}{c}\text { Selera } \\
\text { Pakaian }\end{array}$ \\
\hline 4 & $\begin{array}{l}\text { Contoh } \\
\text { Umum }\end{array}$ & $\begin{array}{c}\text { Sandang, } \\
\text { Pangan, Papan }\end{array}$ & $\begin{array}{l}\text { bermerek, } \\
\text { makan } \\
\text { direstoran }\end{array}$ \\
\hline 5 & $\begin{array}{l}\text { Contoh } \\
\text { Situasi }\end{array}$ & $\begin{array}{l}\text { Haus perlu } \\
\text { minum }\end{array}$ & $\begin{array}{c}\text { Haus } \\
\text { minum } \\
\text { coca cola }\end{array}$ \\
\hline
\end{tabular}


Kebutuhan itu ada batasnya, sedangkan keinginan itu tidak terbatas, maka kita harus selalu bersyukur atas apa yang kita miliki dan mengendalikan diri kita untuk tidak mengikuti keinginan kita.

Sumber penghasilan kita adalah dari gaji, imbalan atas pekerjaan di sebuah perusahaan/organisasi. Selain gaji pokok, ada bonus, THR, dan lainlain; Hasil usaha, hasil dari usaha yang dilakukan, baik secara mandiri maupun bersama orang lain; Investasi, menempatkan uang / dana dengan harapan memperoleh keuntungan atas dana tsb; Pemberian/hadiah, pemasukan tak terduga.

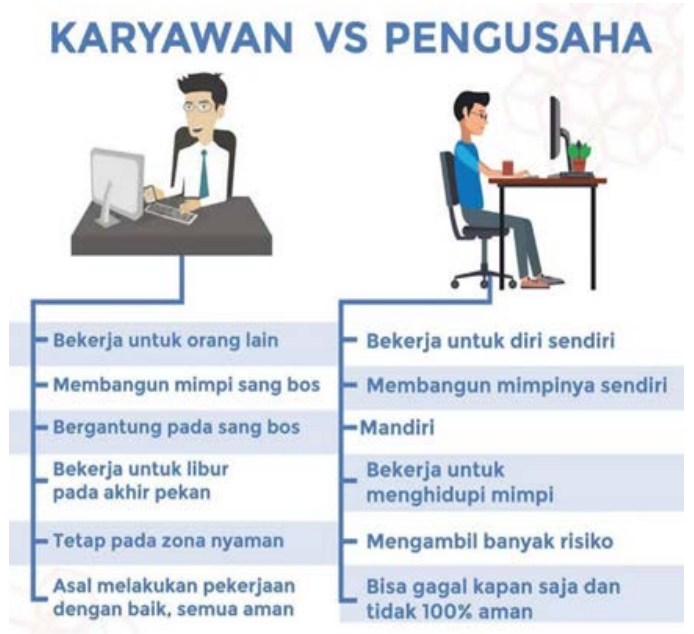

Gambar 1. Karyawan Vs Pengusaha

Perbedaan karyawan dan pengusaha tidak hanya pada gaji dan tunjangan. Tapi lebih kepada faktor risiko, tanggung jawab, peluang menjadi bos, peluang menjadi kaya, pengaturan penghasilan, kepastian dan keamanan. Kita harus memperhatikan faktor-faktor ini jika kita ingin memilih untuk menjadi pengusaha atau karyawan.

Anggaran merupakan suatu
rencana dari penerimaan dan
pengeluaran pada
bulanan/tahunan. Dalam meriode waktu,

anggaran/merencanakan keuangan pribadi, terdapat dua hal yang penting:

Berapa jumlah penerimaan/ uang yang kita terima dan membuat daftar pengeluaran $=>$ kebutuhan rutin. Intinya adalah kita harus bisa membedakan kebutuhan vs keinginan.

\begin{tabular}{|l|l|l|l|}
\hline & Anggaran Penerimaan & Rencana & Altual \\
\hline 1 & Gaii & & \\
\hline 2 & Penerimaan lain-lain & \\
\hline & Total Penerimaan & \\
\hline & Angraran Pengeluaran & Rencana & Altual \\
\hline 1 & Biava makanan & & \\
\hline 2 & Biava transportasi \\
\hline 3 & Biava sewa \\
\hline 4 & Perlengkapan, kebutuhan & \\
\hline 5 & pribadi/rumah tangga \\
\hline 6 & Menabung. \\
\hline 7 & Lain-lain \\
\hline & Total Pengeluaran & \\
\hline
\end{tabular}

Gambar 2. Anggaran Kas

Surplus adalah kondisi jika penerimaan lebih besar daripada pengeluaran. Sedangkan deficit adalah keadaan jika penerimaan lebih kecil daripada pengeluaran.

Manfaat mengelola keuangan adalah menyelamatkan masa depan. Kita tidak tahu, apa yang terjadi di masa yang akan datang. Tapi dengan mengelola keuangan, kita sudah bersiap diri (mawas diri). Siap menyambut masa depan; Uang yang kita peroleh dengan kerja keras, dapat digunakan dengan tepat sasaran, jelas arahnya. Bermanfaat dan mendatangkan kebaikan bagi kita; Kita menjadi hemat dan disiplin dalam menggu-nakan uang, karena kita sudah tahu untuk apa uang tersebut akan digunakan; Kebutuhan utama terpenuhi, sehingga ada sisa uang yang dapat digunakan untuk membeli kebutuhan lainnya.

Risiko jika tidak mengelola keuangan adalah Masa depan yang sulit. Masa depan akan akan kesulitan saat ada sesuatu yang bersifat bencana 
mendadak/ kejadian tak terduga; Menjadi boros dalam menggunakan uang. uang yang dikumpulkan dengan susah payah menjadi terbuang sia-sia; Timbul Utang, Muncul masalah dengan utang-biaya bunga-hidup tidak tenang.

Beberapa hal penting dalam mempraktekkan pengelolaan keuangan yang efektif dan efisien adalah ketahuilah dan sadailah jumlah pemasukan nyata (real) yang kita miliki; daftarkan kebutuhan rutin; miliki tujuan jangka Panjang untuk menentukan jumlah tabungan; realistislah dalam membuat rencana pengelolaan keuangan. Jangan terlalu berambisi sampai menekan pos pengeluaran lain, sebaliknya jangan terlalu santai dan membiarkan semuanya mengalir begitu saja sehingga tujuan kita sulit tercapai; sebisa mungkin, hindari penggunaan kartu kredit; menabunglah dengan menggunakan uanag yang pertama kali kita terima sebelum digunakan, bukannya menabung dengan uang sisa; hidup sederhana; jika memiliki cicilan, jangan sampai melebihi 30\% dari gaji; buatlah pos-pos pengeluaran dalam amplop-amplop yang terpisah sehingga perun-tukannya jelas.

\section{SIMPULAN}

Simpulan dai hasil pelatihan ini adalah pertama, kita harus mengelola dan mengatur keuangan kita dengan bijak. Pengelolaan keuangan tidak membutuhkan pendidikan yang tinggi, dan tidak membutuhkan syarat yang berat, hanya membutuhkan kemauan dan disiplin. Kedua, kita perlu realistis dalam pengelolaan keuanang. Kita jangan memasang target pengelolaan keuangan yang terlalu ketat (sammpai mengorbankan pengeluaran yang penting dan berdampak pada diri), atau terlalu longgar (sampai kita mudah mengingkari rencana tersebut. Ketiga, kita seharusnya membuat evaluasi dan analisis atas penggunaan uang yang dilakukan. Terakhir, analisis dan evaluasi penggunaan uang dibandingkan dengan perencanaan keuangan yang dilakukan dengan kondisi real penggunana uang. Selanjutnya bisa diputuskan perbaikan apa yang perlu dilakukan agar penggunaan uang berjalan lancer sesuai rencana.

\section{UCAPAN TERIMA KASIH}

Ucapan terimakasih kepada Universitas Katolik Indonesia Atma Jaya, Yayasan Bulir Padi dan SMK Pertiwi.

\section{DAFTAR PUSTAKA}

Kementerian Tenaga Kerja, 2019, Modul Mengelola Keuangan Pribadi 